\title{
Lessons learned from market shaping interventions to stimulate vaccine production in LMIC
}

\author{
Evert-jan Quak \\ Institute of Development Studies (IDS) \\ 17 December 2021
}

\section{Question}

What are the lessons learned from using market shaping tools in Africa and other regions to ensure longer term viability and sustainability of vaccines production? If evidence on vaccines is limited, please consider market shaping tools in the wider pharmaceuticals sectors.

\section{Contents}

1. Summary

2. Framing the market-shaping literature

3. Lessons learned from shaping the global vaccine market

4. Market-shaping interventions to stimulate vaccine production in LMICs

5. References

The K4D helpdesk service provides brief summaries of current research, evidence, and lessons learned. Helpdesk reports are not rigorous or systematic reviews; they are intended to provide an introduction to the most important evidence related to a research question. They draw on a rapid deskbased review of published literature and consultation with subject specialists. 


\section{Summary}

This rapid review synthesises the literature from academic, policy, and knowledge institution sources on the lessons learned on how market shaping tools can be used to stimulate vaccine production in low- and middle-income countries (LMICs) with a focus on Africa. The purpose is to learn from these interventions in the context of shaping the vaccine markets in Africa to become less dependent on imports and to stimulate local production of vaccines. The rapid review concludes that it is the combination of market shaping tools (supply and demand sides) with efforts to mobilise resources and a clear industrial policy and strategy with long-term political commitment that is needed to develop fully integrated vaccine facilities in LMICs at the national and regional levels.

Still, a challenge remains that these facilities or "vaccine manufacturing networks" in LMICs, particularly in Africa, will need to sell below their production cost for many years after entering the market. This is because they compete within well-established global vaccine markets to which the low-income countries have access through pooled procurement mechanisms via the GAVI Vaccine Alliance. This means that governments in low-income countries have arguably good access to affordable but imported vaccines (apart from the novel COVID-19 vaccines), while they need heavy investment and high subsidies to develop their own competitive vaccine manufacturers.

The literature on market-shaping is mainly conceptual without mentioning much empirical evidence. Importantly, it has a bias on firms and presumes firm strategies to shape markets for their own benefit. This literature often underestimates the role that governments play in shaping markets (except from the innovation literature). As such, this rapid review relies on other sources to investigate the interventions by governments to shape markets and how donors could support these governments in their efforts. This literature refers to "market-shaping" as a way to intervene in markets in LMICs and has a strong focus on health care (e.g. pharmaceuticals, vaccines). This can be explained because governments themselves are influential buyers in the health market, particularly for vaccines, in which public support and investment is required and returns to investment are high.

Lessons learned from market shaping tools used for vaccine development, manufacturing, and distribution in the context of LMICs mainly come from the global vaccine market. The literature that analysed market-shaping strategies, highlights the following key points:

- The initial strategy that focused on the demand side of the markets with interventions such as centralised demand forecasting, pooled procurement, long-term guarantees for vaccine funding by governments in low-income countries for sustainable volumes could increase incentives to the industry to invest in capacities by reducing the risk of write-offs for manufacturers.

- To cooperate effectively, countries that participate in pooled procurement need well established information sharing system.

- Evidence from GAVI shows that to stimulate new entrants from LMICs in the global vaccine market not only need demand side interventions but need supply side interventions such as risk sharing, technology transfers, capability building and skills development, investment in the right equipment, and reliable regulatory environments. 
- More realistic time for strategic planning and securing donor confidence is needed covering at least 7-10 years.

- Market shaping is stronger when multiple partners contribute and coordinate actions over a long period. This should link manufacturers within regions and with manufacturers outside regions.

- Regulators and government agencies that assure quality of production of vaccines also need to cooperate for example through harmonisation of regulations.

- Vaccine manufacturing networks were mentioned as important to increase flexibility and share experiences, knowledge, and technologies.

- More efforts can be put into creating a neutral organisation to broker partnerships and advising on deal structures.

- Any strategy can only be effective when the industry is backed with enough and longterm financial support which will come mainly from public resources.

The literature distinguishes several interventions for market-shaping (e.g. market information, risk sharing, advance market commitment, push funding), but empirical evidence on the impact on domestic or regional vaccine markets in LMICs (or broader pharmaceuticals) is still scarce. This might be related to the secrecies surrounding obtaining data from these industries. Therefore, this review will highlight some recent initiatives in Latin America and Africa for shaping the vaccine markets and mention some lessons from case studies.

\section{Framing the market-shaping literature}

The literature that introduced the conceptualisation of market-shaping approaches stems from the start of this millennium (Jaworski, Kohli, and Sahay 2000; Narver, Slater, and MacLachlan 2004). It is the response to the "market-driven" discussions of the late 1980s and 1990s on market competitiveness, efficiencies, and innovations. Market shaping relates to the idea of "driving markets" (Jaworski, Kohli, and Sahay 2000) and "proactive market orientation" (Narver, Slater, and MacLachlan 2004), which means influencing the structure of markets and behaviours of the market players. According to Jaworski, Kohli and Sahay (2000) market structures could be changed in three ways: i) deconstruction approach by eliminating players in a market; ii) construction approach by building a new or modified set of players in a market; and iii) functional modification approach by changing the functions performed by market players.

The early literature distanced itself from the general view at that time that markets are static and cannot be shaped beyond market-driven approaches with a focus on "keeping the status quo" of existing customer preferences and market structures (Jaworski, Kohli and Sahay, 2000: 45). In the past twenty years, the literature has conceptualised markets more as "complex adaptive systems encompassing a wide array of market actors beyond the buyer-seller dyad" (Flaig, Kindström, and Ottosson 2021: 254) and considers markets as processes of constant change intentionally and unintentionally. Thus, markets are now perceived to be the outcome of strategies (Storbacka 2019).

Importantly, the market-shaping literature (as the literature on shaping value chains) focuses mainly on the firm's level to increase its competitiveness and create new opportunities and often ignores or underestimates the role of the state in such processes (Horner and Alford 2019; Nenonen, Storbacka, and Windahl 2019). As a response, some of the literature refers to "total 
market approach" which is a system in which the public, private, and social marketing sectors all work together to optimise the market they operate in to achieve a common target (e.g. more vaccines for a lower price) (USAID 2014). In general, the total market approach can be observed mainly in markets with highly specialised capacities and high upfront investments that generate quality goods or services linked to a public good (e.g. health, energy, telecom). ${ }^{1}$

The innovation literature seems the most pronounced in analysing the advanced role that the state has in shaping markets. ${ }^{2}$ Mazzucato (2016) highlights four key policy issues that arise from market-shaping to stimulate innovation for smart growth: i) decision-making on the direction of change; ii) the nature of (public and private) organisations that can welcome the underlying uncertainty and discovery process; iii) the evaluation of mission-oriented and market-creation policies; and iv) the ways in which both risks and rewards can be shared so that smart growth can also result in inclusive growth.

Overall, the literature is clear that governments should only intervene in the market to change the market structure and behaviours of players when they do not disturb competition. The reasons why a government wants to shape markets actively can be narrowed down to two general objectives: i) to make markets work more effective by addressing market failures, and ii) to influence market outcomes to achieve certain policy objectives (e.g., the development of private markets to address a long-term shift in the economy) (Office for Fair Trading (OFT), 2009). To do so governments can participate in the market directly as a supplier (e.g., public services) and buyer (e.g. public procurement), or indirectly through taxes, subsidies, regulations, and influence (e.g., information campaigns) (OFT 2009). Finally, the market-shaping literature has identified four outcome levels based on "market maintenance", "market widening", "market creation", and "market innovation" (Flaig, Kindström, and Ottosson 2021).

\section{Lessons learned from shaping the global vaccine market}

To understand better what market-shaping means in the context of the vaccine markets, this section investigates the literature that analysed the GAVI Alliance global vaccine market approach. The GAVI Alliance's (from now on GAVI) aim is to reduce the historical delay of 15-20 years for new vaccines to reach low-income countries (LICs) at an affordable price. This situation was the result of the low value of LIC vaccine markets which limits competition and a lack of incentives to compete especially in the absence of a large high-income market in which to recover extensive Research \& Development (R\&D) costs (Gehl Sampath 2021). In these markets there is often weak institutional and regulator capacity which delays introduction of new products with malfunctioning public procurement mechanisms.

The result is high-risk aversion and large uncertainties amongst innovating firms, high barriers to entry for new firms, and predatory business models to sustain market positions (with effects on pricing) (Gehl Sampath, 2021). Therefore, GAVl's approach is to lower prices in the vaccine

\footnotetext{
1 Own observation from the author as a result of this literature review.

${ }^{2}$ Not only "Radical Innovation", which is embedded in creating new markets by introducing new technologies, but also more subtle innovations where the source of novelty for market-shaping could be a new way of influencing other aspects of the market, such as work division in the network or institutional arrangements (Nenonen, Storbacka, and Windahl 2019).
} 
market in LICs through a number of market-shaping strategies that could reduce uncertainties (Gilchrist and Nanni 2013). What GAVI initially did was improving demand forecasting for new vaccines, pooling procurement mechanisms for LICs, and combining this with guarantees for long-term funding to purchase vaccines in these countries to increase manufacturers' investments in industrial capacity and supply for vaccines in LICs (Gilchrist and Nanni 2013). Later in the mid-2010s, GAVI's interventions also including technical assistance to manufacturers, improving market information transparency, and risk-sharing agreements aiming to stimulate and capitalise on a competitive market (Malhame et al. 2019).

The key impacts of these interventions on the global vaccine market are:

- There is evidence that GAVI's combined approach of centralised demand forecasting, pooled procurement, and long-term guarantees for vaccine funding in LICs were instrumental to attract additional vaccine suppliers by reducing the risk of write-offs for manufacturers (Gilchrist and Nanni, 2013; Gehl Sampath, 2021).

- The GAVI evaluations also showed that time is an important factor. It took a minimum of seven years before new entrants entered the global market in the case of pentavalent vaccines for GAVI. More vaccine suppliers would mean more competition and ultimately lower prices. Indeed, this was the case for the vaccine market, but at a slower pace than anticipated by GAVI. A more realistic period for strategic planning and securing donor confidence was needed (Gilchrist and Nanni, 2013; Gehl Sampath, 2021).

- The new entrant manufacturers and potential suppliers of lower-priced vaccines were mostly from emerging markets (mainly India). However, these manufacturers typically need around ten years to fully obtain licenses and capacities to produce vaccines that have been developed and introduced to the market by multinational pharmaceutical corporations (Malhame et al. 2019). As such Gilchrist and Nanni (2013: 842) stated that: "the reliance on emerging manufacturers as low-cost producers would seem a feasible strategy, but total reliance would delay new vaccine introductions by several years". ${ }^{3}$

- Risk sharing agreements combined with technical transfers and technical assistance for vaccine manufacturers in emerging markets has resulted in additional supplies of vaccines into the global market and over time significant price reductions were achieved (Gehl, Sampath, 2019). During early market development, technical assistance for manufacturers and government agencies and regulators was essential to ensure quality and efficient regulation and stable supply at reasonable costs (Malhame et al., 2019). However, emerging manufacturers cannot compete directly in the global market, making it difficult for GAVI to push always for the lowest prices. Therefore, in the earlier stages of capacity building and technology transfers, risk-sharing approaches and a tender that does not seek overall cost minimisation supported new actors from emerging markets (Malhame et al., 2019). As the market matured, the strategy was to end risk-sharing interventions and to seek pricing at the costs of production plus a small return.

\footnotetext{
${ }^{3}$ It has also helped foster the emergence of several suppliers such as Serum Institute of India (SII, India), Panacea (India), Biologicals E (India), Bharat Biotech (India), SK Bioscience (South Korea), Chumakov (Russia), Biomanguinhos (Brazil), Chengdu (China), Biofarma (Indonesia), who now supply to GAVI in several vaccine categories (source: Gehl Sampath, 2021).
} 
- Advanced competition has a downside. Supply expansion pushed down prices to a level that some manufacturers had to exit the market. That could be the sign of a healthy market, but in a market with few suppliers, this could result in new monopolies. After a peak of new entries, GAVI had the opportunity to push prices down, but ended with a market in which each of the vaccine categories operates with one or two dominant players (Gehl Sampath, 2021).

- GAVI's inclusion of market information transparency was an important step for countries to utilise market intelligence to inform procurement and market engagement through providing information that can reduce information asymmetries (Malhame et al., 2019). ${ }^{4}$

- As demonstrated in the pentavalent case by Malhame et al. (2019), market shaping is stronger when multiple partners contribute and coordinate actions, while seeking to prevent duplicative or counter-productive work. This is particularly the case for technology transfer. Evidence from the pentavalent market shows that technology transfer by several sources, played a critical role in supply diversification. It was GAVI's additional financial and technical assistance that played an important role in bringing actors together, aligning the supply of technology and finance with global demand for vaccines (Gehl Sampath, 2021). ${ }^{5}$

Based on the GAVI experience, the evidence as presented above shows that for LICs the restructuring of the demand side is important but will not automatically result in new entrants from these countries to the global vaccine market. To let that happen, vaccine manufacturers need "push funding" for product developments, and technology access to increase capacity and scale up production to a competitive level. To cite Gehl Sampath (2021: 12): "In this process, commonly acknowledged factors - such as demand forecasting and financial incentives, as well as technical assistance for quality production work more closely with other important structural incentives, such as lifecycle and steady demand, steady financing for production expansion, technology sharing and product development partnerships to create long- lasting shaping influences."

\footnotetext{
${ }^{4}$ For example, through the WHO's Market Information for Access to Vaccines database for vaccines and/or peer networks such as the Vaccine Procurement Practitioners Network.

\begin{abstract}
5 To cite Gehl Sampath (2021: 8-9): "The pentavalent vaccine, for example, is a conjugate of five antigens, whose production was constrained by a lack of technical know-how related to production and the presence of conjugation patents for one of the antigens $\mathrm{HiB}$ ) in the early 2000s. To overcome this hurdle, the Netherlands Vaccine Institute (NVI) used the PRP-T conjugation method to circumvent competing conjugation patents (Buerett et al, 2012; Hamidi et al, 2014). The technology necessary to produce conjugate Hib (Haemophilus influenzae type B) vaccines was then transferred by the NVI to Biologicals E and SIl in India, Bio Farma in Indonesia, Glovax in South Korea and the Shanghai Institute for Biological Products (SIBP) in China (Buerett et al, 2012) and by GlaxoSmithKline (GSK) to a Brazilian manufacturer (WHO, 2011:11). This technology transfer was instrumental in the entry of Shanta Biotech, Panacea Biotech and SII from India between 2008 and 2011 and helped Bio Farma to enter as a Gavi supplier in 2014. During this time, in addition to the technology transfer for production from NVI, technical assistance was provided by the WHO for pre-qualification (WHO, 2013) and facilitated through PATH and funded by the Gates Foundation to several new suppliers with the intent of furthering investment into building capacity (Malhame et al, 2019)."
\end{abstract}




\section{Market-shaping interventions to stimulate vaccine production in LMICs}

\section{Overview of possible market shaping tools}

In the context of a global vaccine market, the question is if a focus on low prices could damage supply security to LICs and what role local manufacturers in emerging markets could play to increase the access to a high volume of affordable vaccines. The experience of GAVI shows that it needs large scale investments in building production capacity by manufacturers in LMICs, approximated roughly at around USD 100 million per facility to enter the global market (Malhame et al 2019; Nguyen and Schwalbe, 2019). The vaccine manufacturing sector has high fixed costs and therefore needs large markets to spread average costs over large volumes over a reasonable timeframe, which is a significant barrier for new entrants (Nguyen and Schwalbe 2019; Robinson 2016).

Suppliers such as Bio Farma (Indonesia) had supply capacities mainly to meet their domestic demand, while others used the local market as a springboard to enter the global market at a later stage, such as SII and Biologicals E (India) (Gehl Sampath 2021). This also explains why emerging manufacturers are mainly located in large domestic markets such as India, Indonesia, and Brazil. Given the advantages of existing vaccine manufacturers in the market it is difficult for new entrants from new regions and countries with smaller domestic markets to enter the market. This is particularly the case for African suppliers. This means that an approach that includes supplying vaccines for a price that is not necessarily the lowest but still can benefit from the pool procurement mechanism to give them a certain time to settle into the market, build capacity and increase technology transfers and look for other market opportunities (e.g., higher value vaccines or neglected diseases to develop new vaccines) (Gehl Sampath 2021).

What the literature on the market development of vaccines in LMICs shows is that on different levels interventions need to take place in $R \& D$, manufacturing, and regulations (Aars, Clark, and Schwalbe 2021; Nguyen and Schwalbe 2019).

- Despite limited financing and in-house technical capabilities to develop new products, manufacturers in LMICs are increasingly capable of $R \& D$, partly to cooperate with organisations with specialised capabilities for different parts of the development process (Nguyen and Schwalbe 2019). Aars, Clark, and Schwalbe (2021) mention the example of the meningococcal A conjugate vaccine (MenAfriVac). With investment from the Bill \& Melinda Gates Foundation and technical assistance from PATH, the Serum Institute of India developed the first-ever vaccine for Africa and is now the sole global manufacturer.

- On the manufacturing side, knowledge and technology transfers are needed as intellectual property pools to facilitate handover (Nguyen and Schwalbe 2019; Aars, Clark, and Schwalbe 2021). Although the vaccine market experienced such efforts, few agreements are in place for the technology transfer of second-generation vaccines. As such Aars, Clark and Schwalbe (2021) argue that more efforts can be put into creating or engaging with a neutral organisation that could consider a role in brokering partnerships and advising on deal structures. In combination with technical assistance and capacity building processes, this could improve the manufacturing position of manufacturers in LICs (Aars, Clark, and Schwalbe 2021). 
- Vaccine suppliers also need clear regulations that set out the rules and standards for clinical trials, approval and control of vaccines by manufacturers (Nguyen and Schwalbe 2019). Harmonisation of regulatory processes across geographies from clinical trials through to registration and beyond are a step forward and are in progress. Aars, Clark, and Schwalbe (2021) mention the African Vaccine Regulatory Forum (AVAREF) for harmonising regulations for clinical trials and the WHO's prequalification system for lot release. Such efforts are especially important for vaccines with potential for high public health impact (Aars, Clark, and Schwalbe 2021).

Overall, the conclusion is that there is a need for market shaping tools that not only focus on prices (mainly demand side interventions) but also on promotion of new firms' entry to domestic, regional and global markets to keep the vaccine market dynamic (Gehl Sampath, 2021). This includes more structural levers that promote results on the supply side (Gehl Sampath, 2021; USAID 2014) (see Table 1). These interventions will be further examined in the following sections.

Table 1. Levers to shape vaccine markets

\begin{tabular}{|l|l|}
\hline Common market-shaping interventions & Structural levers to shape markets \\
\hline Advance market commitments & Technology transfer \\
\hline Volume guarantees & Technical assistance \\
\hline Pooled procurements & Innovation incentives \\
\hline Market landscape assessments & Simplified registration \\
\hline Demand forecasting & Push funding \\
\hline & Product development partnerships \\
\hline
\end{tabular}

Source: Author's own. Created using data from Gehl Sampath 2021 and USAID 2014

sources: Gehl Sampath 2021; USAID 2014

\section{Levers to reduce high transaction costs in the market}

The USAID (2014) study gives a comprehensive overview of the intervention options available to governments and donors to shape markets in the health care sector. It structures these interventions in three categories based on the root causes of problems faced within the market: high transaction costs, lack of access to timely and trusted market information, out of balance risks between buyers and sellers. 
To reduce transaction costs USAID $(2014)^{6}$ mentions the following interventions:

- Pooled procurement: Orders from multiple buyers, possibly across a range of products, consolidated by a third party who acts as a procurement agent.

- Coordinated ordering: Prices and sales terms negotiated by a third party on behalf of multiple buyers who purchase individually.

- Variant optimisation: Design of guidelines or other arrangements to steer demand toward a specified, optimized set of products.

- Simplified or harmonised registration system: Simplification of the product registration process in one country and/or alignment of registration processes across multiple countries.

- Strengthened quality assurance (QA) system: Improvements to the global or national system for ensuring product quality.

Outside GAVI, African countries are increasingly working on developing such mechanism in the health care sector. See for example the following recent developments:

- Through their middle-income status, Algeria, Botswana, Cabo Verde, Kingdom of Eswatini, Gabon, Mauritius, Namibia, São Tomé and Príncipe and Seychelles have no access to GAVl's pooled procurement for vaccines. Therefore, in 2019 these countries (most of them with small populations) with support by the World Health Organisation (WHO) have established their own pooled vaccine procurement system with the aim to improve access to affordable vaccines and greater stability in their vaccine supply. The countries agreed to coordinate joint market research, sharing vaccine supplier information, monitoring vaccine prices, and coordinated vaccine purchases to increase bargaining power for lower prices. The countries agreed on creating a digital information sharing platform and harmonising immunisation procedures. ${ }^{7}$

- In 2021, the United Nations Economic Commission for Africa (ECA)'s led African Continental Free Trade Area (AfCFTA)-anchored Pharmaceutical Initiative launched the Centralised Pooled Procurement Mechanism (CPPM) for African pharmaceutical enterprises. The idea is that the AfCFTA provides the opportunity to improve access to quality-assured essential medical products while supporting the African pharmaceutical sector through pooled procurement mechanisms. A pilot was launched in 2021 to see how the proposed CPPM and its work programme, time frames work, assurance systems, as well as the establishment of necessary institutional arrangements (secretariat and national levels) for further implementation of the mechanism. The pilot countries are Seychelles, Sudan, Madagascar, Mauritius, Comoros, Djibouti, Eritrea, Rwanda, that are connected to manufacturers in Kenya and Ethiopia - using key reproductive, maternal, newborn, and child health pharmaceutical products. USP developed a database of local manufacturers as way of identifying companies to provide quality assured medicines for the pooled procurements. After the pilot it is envisioned that

\footnotetext{
${ }^{6}$ See for detailed information on benefits, implementation challenges, drawbacks and examples Table 1 on page 31 of USAID (2014).

${ }^{7}$ Information retrieved from the WHO website (December 2021) https://www.afro.who.int/news/nine-african-countries-agreebegin-journey-towards-pooled-procurement-increase-their-access
} 
the framework could be further expanded to other countries and can leverage the capacity of African pharmaceuticals manufacturers. ${ }^{8}$

- The African Union (AU) has established the African Vaccine Acquisition Trust (AVAT) in cooperation with the World Bank to pool their purchasing power which was used for the first time to secure in March 2021 the agreement to purchase 220 million doses of Johnson \& Johnson single-shot COVID-19 vaccine with the potential to order an additional 180 million doses (the remaining vaccines should enter the continent through the COVAX Initiative by international donors). The procured vaccine is partly manufactured (fill-finish activities) in South Africa. The first shipments arrived in August 2021 with a target of delivering 50 million vaccines before the end of December 2021. Countries collaborate with the African Medical Supplies Platform (AMSP) and UNICEF to improve logistical and delivery services. ${ }^{9}$

These recent regional initiatives in Africa build on the successes and lessons from GAVI (see above) and the Pan-American Health Organisation (PAHO) Revolving Fund. Latin American countries make use of $\mathrm{PAHO}$ for coordinated vaccine orders by allocating financial resources to the fund. PAHO serves as the Secretariat. Each time they make a purchase from the Revolving Fund, the country contributes $3.5 \%$ of the net purchase price back into the Fund ( $3 \%$ to be used as working capital, line of credit; $0.5 \%$ for administration costs). ${ }^{10}$ At least $11 \%$ savings in comparison to direct purchases from producers was achieved. ${ }^{11}$ Although the successes made to increase coverage certain challenges remain, such as ensuring universal access to vaccines, especially for the most disadvantaged; maintaining immunisation as a high political priority; and ensuring equitable access by managing the high cost of new vaccines (Etienne 2017). Also, the 'Most favoured nation' clause, whereby suppliers provide PAHO Revolving Fund the lowest available price, was introduced; however, vaccine suppliers have resisted the clause in negotiating prices. ${ }^{12}$

\section{Levers to increase market information}

To increase market information USAID $(2014)^{13}$ mentions the following interventions:

- Market landscape analysis: Review of market structure and dissemination of the findings to highlight strengths and challenges facing product uptake.

\footnotetext{
8 Information retrieved from UNECA and USP websites (December 2021) https://www.usp.org/global-public-health/supportinguneca and https://www.uneca.org/stories/launch-of-the-afcfta-anchored-pharmaceutical-initiative\%E2\%80\%99s-centralisedpooled-procurement

9 Information retrieved from Web Relief website (December 2021) https://reliefweb.int/report/world/africa-announces-rollout400m-vaccine-doses-african-union-member-states-and-caribbean

${ }^{10}$ Information retrieved from http://www.policycures.org/downloads/Policy\%20Brief\%209\%20-\%20Pooled\%20Procurement.pdf (December 2012).

11 idem

12 idem

${ }^{13}$ See for detailed information on benefits, drawbacks, implementation challenges and examples Table 2 on p.33 in USAID (2014).
} 
- Strategic demand forecasting: Aggregation of data and inputs from the major market players to quantify and disseminate a forecast of funded demand.

- Pricing information exchange: Forum for purchasers and suppliers to post sales prices for their transactions, which helps reduce price variations and prevent corruption.

- Quality assessment: Standardized and publicly available assessments of product quality can help procurers evaluate manufacturers and product variants.

Understanding the market and prices for vaccines provides countries with better leverage in procurement negotiations and can inform policies of international development agencies (Cernuschi et al. 2020). In 2014 WHO launched the vaccine product, price, and procurement initiative, referred to as Market Information for Access to Vaccines (MI4A). This aimed to improve vaccine price transparency and therefore support country immunisation planning and budgeting, price negotiation, and, ultimately, improve access to vaccines. The study by Cernuschi et al. (2020) shows the importance of price transparency for fair and lower vaccine prices and understanding market trends on which countries and industries can respond. As the study concludes, there are no obvious signs from the MI4A data that either vaccine availability or prices are negatively affected by greater transparency. "Nevertheless, the increased availability of price data should be monitored to continue to assess both the positive and negative effects of increased transparency on vaccine availability and prices, including the potential for convergence of pricing from different manufacturers" (Cernuschi et al. 2020: 5).

\section{Levers to balance risks}

To improve the risk balance in the health care market USAID $(2014)^{14}$ mentions the following interventions:

- Advance Market Commitment (AMC): Explicit agreement by buyers to guarantee a market for new products that meet a target product profile (TPP) at an agreed-upon price, also referred to as "pull funding".

- Volume guarantee: Explicit agreement by buyers to purchase a minimum quantity of an existing product, typically matched with a long-term supply contract that sets the price for multiple years.

- Promotion incentives: Below-market financing, subsidized marketing activities, or other motivations to increase product promotion efforts among distributors and retailers.

- Channel subsidy: Reduction in the price of the product to consumers by injecting a price subsidy in the distribution channel.

- National essential medicine lists (EML) and guidelines inclusion: Addition of a product to the EML and WHO or national treatment guidelines to increase public sector demand.

- Prize: Competitive crowdsourcing of innovative solutions to global health problems that matches new ideas with technical support and capital.

\footnotetext{
${ }^{14}$ For detailed information on benefits, drawbacks, implementation challenges and examples Table 3 on p.36 in USAID (2014).
} 
Product Development Partnership (PDP): Support for the development of a new product or solution by providing financial support and risk sharing for R\&D to organizations with critical technical expertise.

\section{Box 1. Case study on shaping the pneumococcal conjugate vaccine market}

This case comes from USAID (2014) which state that for the pneumococcal conjugate vaccine (PCV) an Advance Market Commitment (AMC) was put in place in combination with a "multiple winner" structure over a "winner-takes-all" structure. This choice avoided deterring manufacturers from continuing to invest in $R \& D$ if they knew that another manufacturer was closer to product registration. In addition, a multiple winner AMC encourages more than one supplier to participate and thus provides countries with a choice of vaccines. However, with a multiple-winner AMC, the size of an individual incentive is lower because the reward is shared among multiple manufacturers.

Since vaccine manufacturing requires high upfront costs, the AMC designers offset some risk through commitments that guarantee a percentage of each contract with the subsidy. Nevertheless, both vaccine producers GSK and Pfizer stated that the purchase guarantees were insufficient.

By selecting a late-stage vaccine, the AMC designers focused on incentivizing investment in manufacturing capacity rather than $R \& D$. Critics contend that this was a poor use of public funds since there was already a lucrative, high-income market for PCV. Since the pricing models and assumptions were initially not made public, some critics believed that the AMC was overpaying manufacturers.

USAID (2014) mentioned three lessons learned:

- Collaborate from the start - Find strong project advocates to drive the design process and launch.

- Know the trade-offs - Recognize the implications of intervention decisions, such as the selection of a multiple winner structure over a winner-take-all format with the AMC. Transparency on prices is important. In addition, it is important to identify and understand the risks private sector participants face to find ways to share some of the risk with public sector.

- Act soon and adapt - The AMC design process needs to include clear targets to track progress. It is important to adapt to challenges.

Source: USAID (2014)

USAID (2014) did not emphasise capacities of market actors outside R\&D in their publication for shaping the health care markets. However, this point came across various literature on vaccine manufacturing as an important intervention to shape vaccine markets along the need to finance public and private investments (Nguyen and Schwalbe 2019; Aars, Clark, and Schwalbe 2021; Gehl Sampath 2021; Malhame et al. 2019). This is more the terrain of industrial policy and strategy by governments to promote and encourage development and growth of a specific industry. This literature on vaccines mentions the following interventions:

- Push funding: Up-front reimbursement of research, development, and production expenditures to stimulate development of new products and scale up production capacities. 
- Technology transfers: Transferring technology (and related knowledge about the technology) from the technology holders to others who can then further develop and exploit the technology into new products, processes, applications, materials, or services.

- Technical assistance: The process of providing targeted support to build capacity within an organisation with a development need or problem (company, government agencies etc.).

The costs of building and expanding capacities amounts to hundreds of millions of dollars, and needs to be combined with a commitment from governments to purchase vaccines and regulatory bodies that meet international standards. However, there is a trade-off between costs and flexibility (Yadav and Désir 2021). Vaccine developers need the capacity to scale up to reduce costs to an affordable price, but also need to be flexible enough to modify vaccines to target new variants of a virus or to improve technologies within a dynamic market. Therefore, currently, most large vaccine manufacturing facilities specialise in a single product to achieve economies of scale, but this approach is also highly inflexible. As such building in flexibilities comes at a cost. "At large volumes of, say, more than 500 million vaccine doses, flexible manufacturing may not match the economies of scale afforded by dedicated production using large stainless steel or glass vessels/reactors. Indeed, in some instances it may be infeasible due to drastically different operations required for different vaccines" (Yadav and Désir 2021: $\mathrm{n} / \mathrm{a})$.

Supporting the vaccine manufacturers with push funding, capacity building and technology transfers, not only needs a programme design that builds in an analysis of costs and opportunities of flexibilities, but also needs to envision vaccine manufacturing to operate as a network to respond to uncertainties in such a way that an individual manufacturer cannot. Yadav and Désir (2021) show that the optimal option to balance costs and flexibility is a "sparse" network, in which each manufacturer produces two vaccines but the combination of the two is always different in the network. This relates to the discussion about expanding COVID-19 vaccines to vaccine manufacturers in LMICs, which some have argued might be an opportunity to use investments to diversify for combating other diseases such as Zika, yellow fever, diphtheria, pertussis, tetanus, hepatitis B, and Haemophilus influenzae type B (Gehl Sampath 2021).

High investments costs are a problem. Returns on investment cannot be expected in the shortterm while vaccine markets are dynamic and change over time. UNIDO and WHO (2017: 10) calculated that the cheapest investment to establish vaccine manufacturing in LMICs is low volume (10 million doses a year) and formulation and fill only facility, which still needs between USD 14-29 million over 2.5 to 5 years. The same facility at higher volume (30 million doses a year) would cost USD 46-98 million over 5-7 years. However, more value can be added with a fully integrated facility, which at a low volume needs USD 30-65 million investment over 3.5-7 years (using single use technology) while a high-volume facility would cost USD 105-225 million over 7-10 years.

Kazaz, Webster, and Yadav (2021) argue that different forms of finance have different outcomes. Concessional loans by governments or development banks, they argue, could not sufficiently increase the vaccine developer's capacity to a level that society needs. The combination of a concessional loan coupled with capacity subsidy can achieve the desired level of capacity investment at the lowest costs for the implementing agency. "When the government or 
philanthropic organisation has a stronger outlook regarding medium-term demand, but the vaccine developer has a more conservative view of future demand, volume guarantee is the only viable instrument to incentivize socially optimal manufacturing capacity" (Kazaz, Webster and Yadav 2021: n/a).

The African Vaccine Manufacturers Initiative (AVMI) is a partnership platform for the development of vaccine manufacturing capacity in Africa. They actively promote facility partnerships between African manufacturers of vaccines and biologicals and other interested stakeholders with an interest in producing vaccines in Africa. They mobilise resources to invest in new facilities or expand existing facilities and to attract and secure skills, promote academic and technical capacity building in all aspects of production and distribution networks (Ampofo n/a). Furthermore, in April 2021 a new partnership was launched, the Partnership for African Vaccine Manufacturing which seeks for an action agenda to spur cooperation within the regional vaccine market and had been given a push forward in October 2021 by the ratification of $A U$ members to launch the African Medicines Agency (AMA) to harmonize regulations in the continent including vaccine manufacturing processes.

In Latin America, PAHO also committed itself this year to a strategy to increase vaccine production in Latin America. It aims to facilitate the transfer of mRNA technology into Latin America and launched the Regional Platform to Advance the Manufacturing of COVID-19 Vaccines and other Health Technologies in the Americas. Within this platform health, science and technology and industry cooperate to strengthen their capacity to produce new technologies within the region. The distribution of vaccines by PAHO's Revolving Fund is used to guarantee volume and transparency for demand in the region. At the initial stage PAHO has selected two biomedical centres in Argentina and Brazil as regional hubs to develop and produce mRNAbased vaccines to fight COVID-19 in Latin America. The idea is to tap existing manufacturing capacities to help transfer vaccine technology developed by the multinational Moderna. ${ }^{15}$

\section{Box 2. Recent developments in promoting African vaccine manufacturing in the last 6 months} of 2021

Algeria: Launched the local production of Sinovac COVID-19 vaccine (Vero Cell) - CoronaVac.

Egypt: Signed two agreements between Holding Company for Biological Products and Vaccines (VACSERA) and Sinovac for COVID-19 vaccine manufacturing in the country.

Morocco: Signed MOU with the Swedish company "Recipharm" to establish and scale-up COVID-19 vaccine manufacturing capacity.

Rwanda and Senegal signed MOU with BioNTech to establish local mRNA vaccine production plants in Africa

South Africa: The consortium to establish an mRNA technology transfer hub in South Africa to boost vaccine production on the continent brings together the Medicines Patent Pool (MPP), the World

\footnotetext{
15 Information retrieved from https://www.paho.org/en/news/1-9-2021-paho-launches-new-collaborative-platform-produce-covid19-vaccines-latin-america-and
} 
Health Organization (WHO), Afrigen Biologics Limited, the Biologicals and Vaccines Institute of Southern Africa (Biovac) and the South African Medical Research Council (SAMRC) and Africa CDC.

Establishment of a vaccine industry talent development program in partnership with MasterCard Foundation

Coordinated development of local manufacturing capacity on the continent in partnership with the Team Europe Initiative on manufacturing and access to medicines, vaccines and health technologies is considered in different countries.

Source: CDC Africa website ENGLISH_PAVM_Public-Stakeholder-Engagement_Concept-note_Finalversion.pdf (africacdc.org)

\section{References}

Aars, Ole Kristian, Michael Clark, and Nina Schwalbe. 2021. 'Increasing Efficiency in Vaccine Production: A Primer for Change'. Vaccine: X 8 (August): 100104. https://doi.org/10.1016/j.jvacx.2021.100104.

Ampofo, William. n/a. 'Vaccine Manufacturing in Africa: Self-Sufficiency a Need or a Dream?' https://www.who.int/immunization/research/forums_and_initiatives/1_Wlliam_Ampofo_Vaccin e_Manufacturing_Africa.pdf?ua=1.

Cernuschi, Tania, Shawn Gilchrist, Adnan Hajizada, Melissa Malhame, Stephanie Mariat, and Greg Widmyer. 2020. 'Price Transparency Is a Step towards Sustainable Access in Middle Income Countries'. BMJ 368 (January): I5375. https://doi.org/10.1136/bmj.I5375.

Etienne, Carissa. 2017. 'Expanded Program on Immunization in the Americas: 40 Years'. Revista Panamericana de Salud Pública 41 (December): e139. https://doi.org/10.26633/RPSP.2017.139.

Flaig, Alexander, Daniel Kindström, and Mikael Ottosson. 2021. 'Market-Shaping Strategies: A Conceptual Framework for Generating Market Outcomes'. Industrial Marketing Management 96 (July): 254-66. https://doi.org/10.1016/j.indmarman.2021.06.004.

Gehl Sampath, Padmashree. 2021. 'Market Shaping and Market Access in the Global Vaccines Market: Approaches for the Future'. SSRN Scholarly Paper ID 3945668. Rochester, NY: Social Science Research Network. https://doi.org/10.2139/ssrn.3945668.

Gilchrist, Shawn A.N., and Angeline Nanni. 2013. 'Lessons Learned in Shaping Vaccine Markets in Low-Income Countries: A Review of the Vaccine Market Segment Supported by the GAVI Alliance'. Health Policy and Planning 28 (8): 838-46. https://doi.org/10.1093/heapol/czs123.

Horner, Rory, and Matthew Alford. 2019. 'The Roles of the State in Global Value Chains: An Update and Emerging Agenda', January.

https://www.research.manchester.ac.uk/portal/en/publications/the-roles-of-the-state-in-globalvalue-chains-an-update-and-emerging-agenda(23e6a77c-b132-4c2c-8ed1b4068cf23ae3).html.

Jaworski, Bernard, Ajay K. Kohli, and Arvind Sahay. 2000. 'Market-Driven versus Driving Markets'. Journal of the Academy of Marketing Science 28 (1): 45-54. https://doi.org/10.1177/0092070300281005.

Kazaz, Burak, Scott Webster, and Prashant Yadav. 2021. 'How Can We Encourage COVID-19 Vaccine Developers to Expand Manufacturing Capacity?' Centre for Global Development 
(blog). March 2021. https://www.cgdev.org/blog/how-can-we-encourage-covid-19-vaccinedevelopers-expand-manufacturing-capacity.

Malhame, Melissa, Edward Baker, Gian Gandhi, Andrew Jones, Philipp Kalpaxis, Robyn Iqbal, Yalda Momeni, and Aurelia Nguyen. 2019. 'Shaping Markets to Benefit Global Health - A 15-Year History and Lessons Learned from the Pentavalent Vaccine Market'. Vaccine: X 2 (August): 100033. https://doi.org/10.1016/j.jvacx.2019.100033.

Mazzucato, Mariana. 2016. 'From Market Fixing to Market-Creating: A New Framework for Innovation Policy'. Industry and Innovation 23 (2): 140-56. https://doi.org/10.1080/13662716.2016.1146124.

Narver, John C., Stanley F. Slater, and Douglas L. MacLachlan. 2004. 'Responsive and Proactive Market Orientation and New-Product Success*'. Journal of Product Innovation Management 21 (5): 334-47. https://doi.org/10.1111/j.0737-6782.2004.00086.x.

Nenonen, Suvi, Kaj Storbacka, and Charlotta Windahl. 2019. 'Capabilities for Market-Shaping: Triggering and Facilitating Increased Value Creation'. Journal of the Academy of Marketing Science 47 (4): 617-39. https://doi.org/10.1007/s11747-019-00643-z.

Nguyen, Aurelia, and Nina Schwalbe. 2019. 'Apples and Oranges? Can Second Generation Vaccines Become as Low Cost as Generic Medicines?' Vaccine 37 (22): 2910-14. https://doi.org/10.1016/j.vaccine.2019.04.016.

OFT. 2009. 'Government in Markets: Why Competition Matters - a Guide for Policy Makers'. Office for Fair Trading.

https://assets.publishing.service.gov.uk/government/uploads/system/uploads/attachment_dat a/file/284451/OFT1113.pdf.

Robinson, James M. 2016. 'Chapter 5 - Vaccine Production: Main Steps and Considerations'. In The Vaccine Book (Second Edition), edited by Barry R. Bloom and Paul-Henri Lambert, 77-96. Academic Press. https://doi.org/10.1016/B978-0-12-802174-3.00005-9.

Storbacka, Kaj. 2019. 'Actor Engagement, Value Creation and Market Innovation'. Industrial Marketing Management 80 (July): 4-10. https://doi.org/10.1016/j.indmarman.2019.04.007.

USAID. 2014. 'Healthy Markets for Global Health: A Market Shaping Primer'. Washington, D.C.: USAID Global Health. https://www.usaid.gov/sites/default/files/documents/1864/healthymarkets_primer.pdf.

Yadav, Prashant, and Antoine Désir. 2021. 'Boosting Vaccine Production Needs the Right Degree of Flexibility'. INSEAD Knowledge (blog). November 2021. https://knowledge.insead.edu/operations/boosting-vaccine-production-needs-the-right-degreeof-flexibility-17621.

\section{Acknowledgements}

I would like to thank the following expert who voluntarily provided suggestions for relevant literature or other advice to support the preparation of this report. The content of the report does not necessarily reflect the opinions of any of the experts consulted.

- Anabel Marin - Research Fellow and lead of the Business Market and the State research cluster at the Institute of Development Studies (IDS) in Brighton. 


\section{Suggested citation}

Quak, E. (2021). Lessons learned from market shaping interventions to stimulate vaccine production in LMIC. K4D Helpdesk Report no.1072. Brighton, UK: Institute of Development Studies. DOI: 10.19088/K4D.2022.009

\section{About this report}

This report is based on six days of desk-based research. The K4D research helpdesk provides rapid syntheses of a selection of recent relevant literature and international expert thinking in response to specific questions relating to international development. For any enquiries, contact helpdesk@k4d.info.

K4D services are provided by a consortium of leading organisations working in international development, led by the Institute of Development Studies (IDS), with Education Development Trust, Itad, University of Leeds Nuffield Centre for International Health and Development, Liverpool School of Tropical Medicine (LSTM), University of Birmingham International Development Department (IDD) and the University of Manchester Humanitarian and Conflict Response Institute (HCRI).

This report was prepared for the UK Government's Foreign, Commonwealth, and Development Office (FCDO) and its partners in support of pro-poor programmes. It is licensed for noncommercial purposes only. K4D cannot be held responsible for errors or any consequences arising from the use of information contained in this report. Any views and opinions expressed do not necessarily reflect those of FCDO, K4D or any other contributing organisation.

(C) FCDO- Crown copyright 2021.

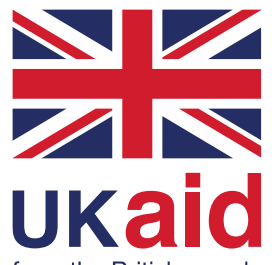

